\title{
Global research trends in COVID-19 with MRI and PET/CT: a scoping review with bibliometric and network analyses
}

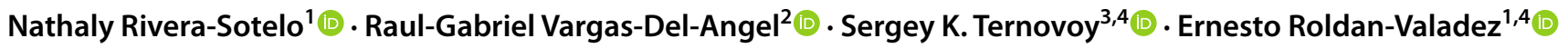

Received: 21 June 2021 / Accepted: 4 August 2021 / Published online: 14 August 2021

(C) Italian Association of Nuclear Medicine and Molecular Imaging 2021

\begin{abstract}
Objective To identify and evaluate the indexed studies that allow us to understand the implications of imaging studies in MRI and PET/CT related to COVID-19 research.

Methods Scoping review. Articles in PubMed, Scopus, and Web of Science (WoS) were scanned from 2019 to 2021 with COVID-19, MRI, and PET-CT as keywords. EndNote software and manual checking removed the duplicated references. Our assessment includes citation, bibliometric, keyword network, and statistical analyses using descriptive statistics and correlations. Highlighted variables were publication year, country, journals, and authorship.

Results Only 326 papers were included. The most cited article reached 669 cites; this number represented $21.71 \%$ of 3081 citations. The top-15 cited authors received 1787 citations, which represented 58\% of the total cites. These authors had affiliations from ten countries (Belgium, China, France, Italy, Japan, Spain, Sweden, Turkey, United Kingdom (UK), and the USA). The top-30 journals were cited 2762 times, representing $89.65 \%$ of the total cites. Only five journals were cited more than 100 times; Int J Infect Dis had the most significant number of citations (674). Some of the unexpected keywords were encephalitis, stroke, microbleeds, myocarditis.

Conclusion COVID-19 pandemic is still spreading worldwide, and the knowledge about its different facets continues advancing. MRI and PET/CT are being used in more than 50\% of the selected studies; research trends span seven categories, no only the diagnostic but others like socio-economic impact and pathogenesis Developed countries had an advantage by having hospitals with more resources, including MRI and PET/CT facilities in the same institution to supplement basic assessment in patients with COVID-19.
\end{abstract}

Keywords COVID-19 $\cdot$ MRI $\cdot$ PET $\cdot$ CT $\cdot$ Bibliometric analysis $\cdot$ Data visualization

Ernesto Roldan-Valadez

ernest.roldan@usa.net

Nathaly Rivera-Sotelo

n.rivera.sotelo@gmail.com

Raul-Gabriel Vargas-Del-Angel raul.vda1995@hotmail.com

Sergey K. Ternovoy prof_ternovoy@list.ru

1 Directorate of Research, Hospital General de Mexico "Dr Eduardo Liceaga”, 06720 Mexico City, Mexico

2 Hospital de Oncología, Centro Medico Nacional Siglo XXI, Instituto Mexicano Del Seguro Social, Mexico City, Mexico

3 Department of Radiology, A.L. Myasnikov Research Institute of Clinical Cardiology of National Medical Research Center, Moscow, Russia

4 Department of Radiology, I.M. Sechenov First Moscow State Medical University (Sechenov University), 119992 Moscow, Russia

\section{Introduction}

\section{Assessing the influence of publications in medical research}

An accurate assessment to determine the influence of medical papers is fundamental for improving physicians' ability to identify essential articles in a specific scientific research field. This activity also guides clinical practice decisions; as the number of articles that researchers need to be familiar with increases, so does the importance of selective searching and generalization [1].

\section{Coronavirus disease 2019 (COVID-19)}

Two well-known b-coronaviruses caused severe disease with considerably high mortality rates in recent memory, 
the severe acute respiratory syndrome coronavirus 1 (SARS-CoV-1) and Middle East respiratory syndrome (MERS) epidemics [2, 3]. The novel SARS-CoV-2 b-coronavirus driving the current coronavirus disease 2019 (COVID-19) pandemic has depicted transmission rates far above those seen during prior b-coronavirus epidemics [4]. COVID-19 emerged in December 2019 and rapidly developed into a global outbreak [5].

COVID-19 patients may be asymptomatic or present no specific signs and symptoms like fever, dyspnea, and cough; this lack of specif clinical features can increase the risk of spread of the epidemic [6]. It is accepted that the clinical manifestations of COVID-19 show a significant overlap in presentation with other respiratory tract infections, such as the influenza virus, which makes its diagnosis based on clinical grounds challenging [7], especially during the year when the flu is epidemic [8]. SARS-CoV-2 infection cannot be entirely excluded, even if reversetranscription polymerase chain reaction (RT-PCR) results are negative [9]; also, a high false-negative rate has been reported, which can cause a miss or delay in the effective diagnosis [10]. Therefore, medical imaging is a complementary examination in the diagnosis and management of COVID-19 [11].

\section{MRI and COVID-19}

Although radiologic imaging's utility in screening and diagnosing suspected COVID-19 cases has been hotly debated since the start of the pandemic [7], chest imaging has played an essential role in both the case definition and clinical classification of COVID-19 [11]. In day-to-day practice, radiologists stratify cases of COVID-19 based on radiologic imaging to identify those patients most at risk for imminent clinical decompensation [12,13].

At least three studies have compared pulmonary magnetic resonance imaging (MRI) features of COVID-19 pneumonia against conventional chest computed tomography $(\mathrm{CT})$. It is possible the visualization of groundglass opacities (GGOs), consolidation, reticulation, and a reverse halo sign on multiple MRI sequence [14], with no significant differences in MRI detection of GGOs or consolidative lesions versus conventional CT [15]. Ultrashort echo time MRI (UTE-MRI) vs. conventional CT has demonstrated high concordance in lesion detection [16]. Current guidelines from the American College of Radiology recommend limiting the use of MRI in confirmed or suspected SARS-CoV-2-positive patients [16, 17]. MRI may provide a viable alternative for imaging high-risk patient groups (pregnant patients and children, in whom exposure to ionizing radiation should be avoided) $[14-16,18,19]$.

\section{PET and COVID-19}

Recent studies have evinced a growing role in using positron emission tomography (PET) to evaluate and characterise infectious and inflammatory pulmonary conditions [20-22]. A recent study that assessed the presence and pattern of incidental interstitial pneumonia due to COVID19 on fluorine-18fluorodeoxyglucose positron emission tomography/computed tomography (PET/CT) in asymptomatic oncological patients, found a rate of $7.1 \%$ during the COVID period compared with $5.35 \%$ pre-COVID period; the detection rate was $59 \%$ with a maximum standardized uptake (SUVmax) of 4.1 [6].

It is known that acute lung injury in viral pneumonia is driven by chemokine recruitment of neutrophils, monocytes, and effector $\mathrm{T}$ cells $[21,23]$. Neutrophil activity manifests as ${ }^{18} \mathrm{~F}$-FDG-avid foci on PET imaging [7]. Viral replication occurs in the absence of clinical manifestations of the disease [24]. Therefore PET/CT has been proposed as an alternative modality to detect early, subclinical infections, albeit with an associated radiation cost [21,23]. COVID-19 pneumonia has shown parenchymal ${ }^{18}$ F-FDG uptake in regions corresponding to GGOs and consolidative opacities, with maximum standardized uptake (SUVmax) values ranging from 4.6 to 12.2 [25]. This radiotracer uptake has also been noted in the hilar and paratracheal lymph nodes and the bone marrow [26]. A systematic review reported a mean SUVmax of $4.9 \pm 2.3$ in COVID19-associated pulmonary lesions [27]. Two radiotracers used in the setting of prostate cancer, the ${ }^{68} \mathrm{Ga}$-labelled prostate-specific membrane antigen $\left({ }^{68} \mathrm{Ga}\right.$-PSMA) and ${ }^{18} \mathrm{~F}$-labelled choline $\left({ }^{18} \mathrm{~F}\right.$-choline $)$, have identified hypermetabolic lesions corresponding to subpleural GGOs [28]. A greater ${ }^{18} \mathrm{~F}$-FDG uptake may correlate with higher erythrocyte sedimentation rates and a longer time to heal $[21,25,29] .{ }^{18} \mathrm{~F}$-FDG PET/CT may also help assess for changes in other organ systems, including the heart, kidneys, and gastrointestinal tract [29], and the presence of concomitant infections in situations of diagnostic uncertainty [30].

\section{Purpose of the study}

We found more than 83,000 articles, including the phrase COVID-19, in the title of articles indexed in the National Library of Medicine (PubMed) of USA until April 7th of 2021. A systematic review of the research trends in MRI and PET in COVID-19 has not yet been described. We aimed to identify and evaluate the indexed studies that allow us to understand the implications of research imaging in MRI and PET/CT articles related to COVID-19 research. 


\section{Methods}

\section{Scoping review}

A scoping review describes existing literature and other sources of information and commonly includes findings from various study designs and methods [31]. Its purpose is to provide an overview of the available research evidence without producing a summary answer to a discrete research question [32]. For developing this study, we followed the Arksey and O'Malley approach framework, which summarises five stages for reporting a scoping review [32]: (1) identify the research question; (2) identify relevant studies; (3) study selection; (4) chart the data; and (5) collate, summarise, and report the results. Levac et al. [33] and the Joanna Briggs Institute [34] updated the methodological framework. This study also was abided by the Preferred Reporting Items for Systematic reviews and Meta-Analyses extension for Scoping Reviews (PRISMA-ScR) Checklist [35] and recent methodology for reporting systematic quantitative reviews [36]. This data-driven analysis did not require ethical approval, all data are in the public domain and collated data are included in this paper.

\section{Identifying the research question}

Considering that radiological tools such as chest X-rays and $\mathrm{CT}$ in detecting COVID-19-related interstitial pneumonia have already been accepted as imaging criteria for the final diagnosis [37-39]; we wanted to know the helpfulness of other imaging methods that were avaible in tertiary care hospital during the COVID-19 pandemia. Then, our question was: What is known from the existing research in the field of "imaging in COVID-19 using MRI and PET/CT"?

\section{Identifying databases and relevant studies}

Articles were retrieved from PubMed, Scopus, and Web of Science (WoS) with the period restricting from 1st January 2019 to April 9th 2021 (the date when we performed the search on the selected databases), using the search terms "COVID-19", "MRI", and "PET/CT".

We included independent search algorithms considering the selected databases' specific search terms and commands (Supplementary file, Table A).

\section{Study selection}

Two reviewers selected the articles with predefined inclusion and exclusion criteria (Supplementary Table A) independently (N.R.S. and R.G.V.A.); any discrepancy was resolved by discussion. Initial filtering methods included the period (2019-2021), and language limited to English, subsequent filtering through title and abstract to exclude the irrelevant articles, the final screening was done by reading the fulltext version of each article. After running search strategies specific for each database, we removed the retrieved articles' duplications using the EndNote ${ }^{\circledR}$ software (version X9.3.3, (C) 2020 Clarivate Analytics, Boston, MA, USA). By following the recent guidelines for Scoping Reviews [35], the study's flowchart is presented in Fig. 1.

\section{Articles demographics, citation and bibliometric analyses}

Data regarding journals, publication year, country and author were collected. Qualified articles were ranked in descending order by the citation number.

\section{Journals' bibliometric analyses}

Six bibliometrics corresponding to the journals of selected publications were analyzed to evaluate journals' impacts: Impact factor (IF), Eigenfactor score (ES), CiteScore, Source Normalized Impact per Paper (SNIP), SCImago Journal Rank (SJR) and Quartile (from Q1 to Q4). Journals with a higher score of these indicators are generally considered more prestigious than those with lower scores [40].

\section{Global research trends in COVID-19}

Three variables were recorded to evaluate this field: type of article, research direction, and imaging tool. The type of article included seven categories: (1) prospective study; (2) retrospective study; (3) randomized clinical trial (RCT); (4) case report or case series; (5) basic science research; (6) consensus and guidelines, and (7) case and control studies.

The research direction of the articles was recorded by classifying them in eight categories: (1) aetiology and pathogenesis; (2) epidemiology and demographics; (3) pathophysiology; (4) diagnosis, clinical characteristics, or complications; (5) treatment; (6) prognostic; (7)=Socio-economic impact; and (8) multidirectional studies (two or more categories). The imaging method used in COVID-19 research had three options: (1) MRI; (2) PET/CT; (3) both methods.

\section{Network analysis of keyword cooccurrences}

Network analysis is used to reveal the scientific structure, the degree of subject correlation, literature retrieval, and others, starting from the topic correlation reflected in the citations. We performed a network analysis of the keyword correlation of selected publications. This keywords analysis can identify a research topic by closely related publications in citation 


\section{PubMed}

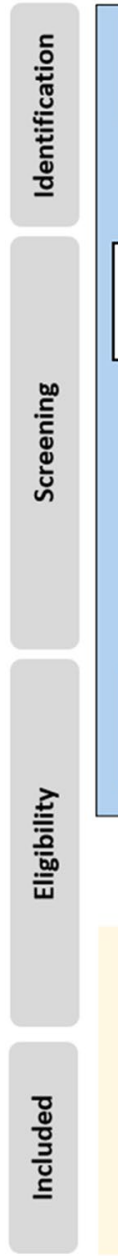

imit to Clinical trials $(n=187)$
Scopus

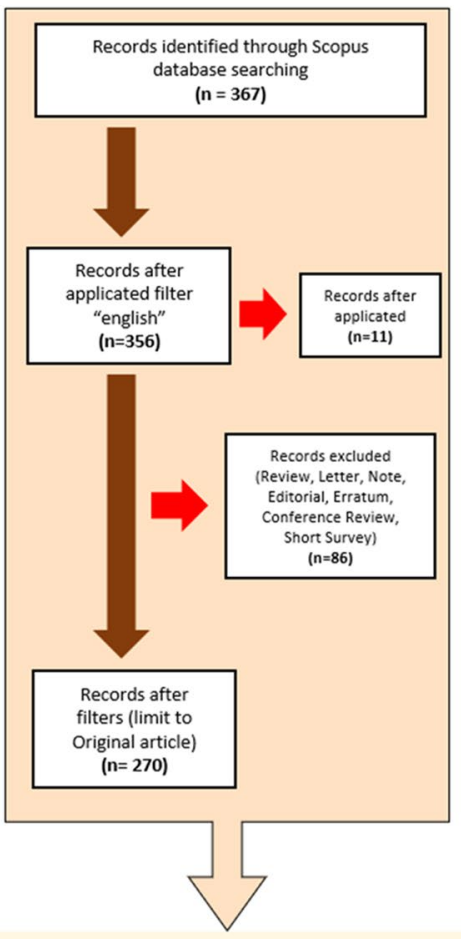

\section{Web of Science}

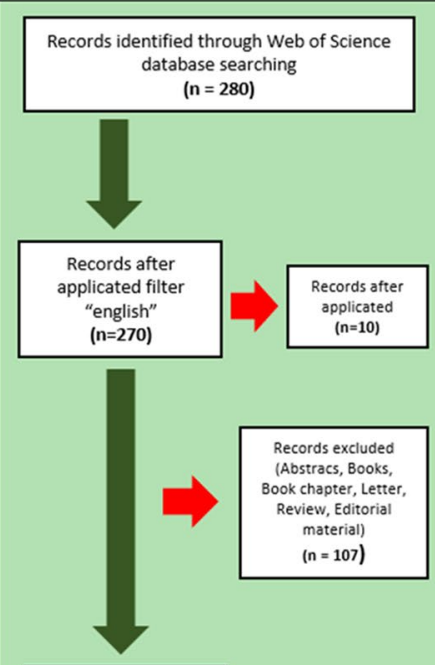

Records after

(n=163)
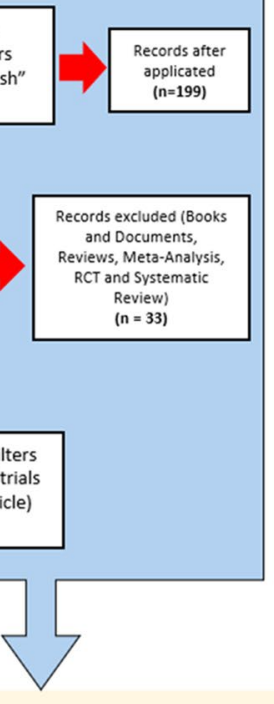

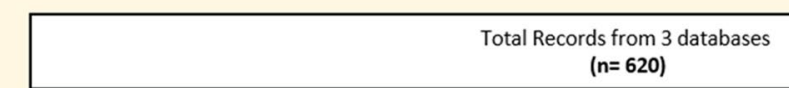

$(n=620)$

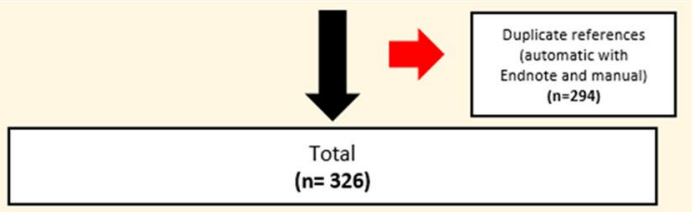

Fig. 1 Flowchart of the study

relations [1]. Network analysis allows the detection of current research hotspots in the field of interest.

VOSviewer (version 1.6.16, Leiden University, The Netherlands) was applied to perform network analyses. We selected "all keywords" as the unit of analysis and set the minimum number of occurrences of a keyword to 5 . VOSviewer allowed us to build network analysis of bibliometric relations using large-scale data. We used the density visualization mode. The yellow nodes indicate increased weights of the neighbouring items; the node changes toward blue as the neighbouring items' weights decrease. The size of the node increases with the number of items in the neighbourhood [41].

\section{Software used for database creation, statistical analysis and data visualization}

We used Microsoft Excel v16.33 (Microsoft Corporation, Redmon, WA, USA) to manage the database created with
EndNote. The IBM ${ }^{\circledR}$ SPSS ${ }^{\circledR}$ Statistics software (version 26.0.0.1 IBM Corporation; Armonk, NY, USA) and JMP ${ }^{\circledR}$ Pro software (version 14.3, SAS Institute Inc., Cary, NC, USA) helped us designing frequency tables, bar graphs, parallel coordinates plot and Spearman correlations analysis to compare correlations between bibliometrics of the journals of selected articles. The methodology for using a correlation matrix in bibliometrics has been previously described [42]. Statistical significance was indicated by $p<0.05$ (two-tailed).

Data visualization of a flowchart for PRISMA-ScR (Fig. 1) used Microsoft PowerPoint v16.33 (Microsoft Corporation, Redmon, WA, USA); mapping used (CTableau software (version 2019.1.3, Seattle, Washington, USA). Microsoft PowerPoint and (Tableau software for data visualization have been previously described [43-45]. 


\section{Results}

\section{Selected articles}

Six hundred and twenty articles were retrieved from PubMed, Scopus, and WoS (after filters in each platform). The three databases yielded 419, 367, and 280 papers, respectively. The EndNote software removed 210 duplications; 84 publications were excluded after screening the title, abstract and reviewing the full text according to the inclusion or exclusion criterion. Only 326 papers meeting all identified requirements were included. Figure 1 shows the selected papers based on the PRISMA-ScR guidelines. The complete list of selected articles is included as Table B of a supplementary online-only file.

\section{Total citations, authors, time of publication, and countries' analyses}

\section{Total citations analysis}

The Kolmogorov-Smirnov and Shapiro-Wilk tests for normality showed a non-normal distribution of the total citations. For that reason, we did not use the mean and standard deviation but the median, quartiles and interquartile range (IQR) to describe central tendency values for this variable. The median for the total cites was 2 with a 75-percentile value of 6; Table $\mathrm{C}$, in the supplementary file summarises the selected articles' descriptive statistics.

The most cited article reached 669 cites; this number represented $21.71 \%$ of 3081 citations. Only four articles were cited more than 100 times [Int J Infect Dis. 2020 May;94:55-58. Brain. 2020 Oct 1;143(10):3104-3120. Eur J Nucl Med Mol Imaging. 2020 May;47(5):1281-1286. Acta Neurochir (Wien). 2020 Jul;162(7):1491-1494]. Only ten articles received between 51 and 100 cites; 98 articles did not receive any citation, equivalent to the $30.24 \%$ of the total number of selected articles. A frequency table of Total cites is included as Table $\mathrm{D}$, in the supplementary online-only file.

\section{Authors' citation analysis}

The top- 15 cited authors received 1787 citations [25, 26, 46-58], which represented $58 \%$ of the total cites. These authors had affiliations from ten countries (Belgium, China, France, Italy, Japan, Spain, Sweden, Turkey, United Kingdom (UK), and the USA). Moriguchi T. from Japan collected the highest number of citations, 669; Wong P. from the UK received the lowest number of citations, 43 , in this top-15 group. Table 1 shows the top-15 cited articles in COVID-19, MRI and PET/CT research.

\section{Date of publication analysis}

PET and MRI publications in the context of COVID-19 appeared as early as February 2020. The average number of publications per month was 22. Since August 2020, the number of publication had been above the mean, but with an apparent decremental trend since January 2021. Figure 2 shows a bar graph with the number of publications per month.

\section{Country of publication analysis}

Forty-seven countries from all continents published the 326 selected articles, the top-five countries with publications were the USA (82), Italy (31), France (28), United Kingdom (28), and Spain (24); the sum of these articles represented $59.3 \%$ of the $100 \%$ (326) selected articles. A frequency table of countries is included in Table $\mathrm{E}$ in the supplementary online-only file. Figure 3 shows a global map of the published articles around the world.

\section{Journals' analyses of total citations, number of articles and Average no. of citations per paper}

We recorded 166 journals from articles that fulfil the inclusion criteria; from those, only 108 journals had at least one citation. The mean number of citations for all journals was 28.53 , and the range was from 1 to 674 . The top-30 journals were cited 2,762 times, representing $89.65 \%$ of the total cites; the range of citations for those journals was from 14 to 674 .

Only five journals were cited more than 100 times; Int J Infect Dis had the most significant number of citations (674), followed by Radiology (469), Eur J Nucl Med Mol Imaging (216), Brain (207) and Acta Neurochir (Wien) (110). When we sorted the journals by descending the number of average citations, IEEE Rev Biomed Eng entered the top five journals. If we sorted the journals by descending the number of articles, the list of the top five journals changed to Eur J Nucl Med Mol Imaging (23), Clin Nucl Med (22), Radiology (9), BMJ Case Rep (9), and Acad Radiol (7).

Considering the 108 journals that received at least one citation, there was a moderate strength of Spearman correlation coefficient between the number of citations of each journal and their number of published articles $(\mathrm{Rs}=0.525$, $p<0.001)$. Table 2 shows the top-30 cited journals in COVID-19, MRI and PET/CT research. 
Table 1 Top-15 cited articles in COVID-19, MRI and PET/CT research [25, 26, 46-58]

\begin{tabular}{|c|c|c|c|c|c|c|}
\hline Rank & First autor & Journal & Title & No. Cites & Country & Year \\
\hline 1 & Moriguchi, T & Int J Infect Dis & $\begin{array}{l}\text { The first case of meningitis/enceph- } \\
\text { alitis associated with SARS- } \\
\text { Coronavirus-2 }\end{array}$ & 669 & Japan & 2020 \\
\hline 2 & Paterson, R. W & Brain & $\begin{array}{l}\text { The emerging spectrum of COVID- } \\
19 \text { neurology: clinical, radiologi- } \\
\text { cal and laboratory findings }\end{array}$ & 156 & United Kingdom & 2020 \\
\hline 3 & Qin, C & Eur J Nucl Med Mol Imaging & $\begin{array}{l}\text { (18)F-FDG PET/CT findings of } \\
\text { COVID-19: a series of four highly } \\
\text { suspected cases }\end{array}$ & 132 & China & 2020 \\
\hline 4 & Zanin, L & Acta Neurochir (Wien) & $\begin{array}{l}\text { SARS-CoV-2 can induce brain and } \\
\text { spine demyelinating lesions }\end{array}$ & 110 & Italy & 2020 \\
\hline 5 & Kremer, S & Radiology & $\begin{array}{l}\text { Brain MRI Findings in Severe } \\
\text { COVID-19: A Retrospective } \\
\text { Observational Study }\end{array}$ & 94 & France & 2020 \\
\hline 6 & Kandemirli, S. G & Radiology & $\begin{array}{l}\text { Brain MRI Findings in Patients } \\
\text { in the Intensive Care Unit with } \\
\text { COVID-19 Infection }\end{array}$ & 82 & Turkey & 2020 \\
\hline 7 & Radmanesh, A & Radiology & $\begin{array}{l}\text { COVID-19-associated Diffuse } \\
\text { Leukoencephalopathy and Micro- } \\
\text { hemorrhages }\end{array}$ & 82 & United States & 2020 \\
\hline 8 & Albano, D & J Nucl Med & $\begin{array}{l}\text { Incidental Findings Suggestive } \\
\text { of COVID-19 in Asymptomatic } \\
\text { Patients Undergoing Nuclear } \\
\text { Medicine Procedures in a High- } \\
\text { Prevalence Region }\end{array}$ & 77 & Italy & 2020 \\
\hline 9 & Bhayana, R & Radiology & $\begin{array}{l}\text { Abdominal Imaging Findings in } \\
\text { COVID-19: Preliminary Observa- } \\
\text { tions }\end{array}$ & 72 & United States & 2020 \\
\hline 10 & Dixon, L & $\begin{array}{l}\text { Neurol Neuroimmunol Neuroin- } \\
\text { flamm }\end{array}$ & $\begin{array}{l}\text { COVID-19-related acute necrotiz- } \\
\text { ing encephalopathy with brain } \\
\text { stem involvement in a patient } \\
\text { with aplastic anaemia }\end{array}$ & 61 & United Kingdom & 2020 \\
\hline 11 & Coolen, $\mathrm{T}$ & Neurology & $\begin{array}{l}\text { Early postmortem brain MRI find- } \\
\text { ings in COVID-19 non-survivors }\end{array}$ & 55 & Belgium & 2020 \\
\hline 12 & Zou, S & Radiology & FDG PET/CT of COVID-19 & 52 & China & 2020 \\
\hline 13 & Hernandez-Fernandez, F & Brain & $\begin{array}{l}\text { Cerebrovascular disease in patients } \\
\text { with COVID-19: neuroimaging, } \\
\text { histological and clinical descrip- } \\
\text { tion }\end{array}$ & 51 & Spain & 2020 \\
\hline 14 & Virhammar, J & Neurology & $\begin{array}{l}\text { Acute necrotizing encephalopathy } \\
\text { with SARS-CoV-2 RNA con- } \\
\text { firmed in cerebrospinal fluid }\end{array}$ & 51 & Sweden & 2020 \\
\hline 15 & Wong, P. F & Clin Med (Lond) & $\begin{array}{l}\text { Lessons of the month 1: A case } \\
\text { of rhombencephalitis as a rare } \\
\text { complication of acute COVID-19 } \\
\text { infection }\end{array}$ & 43 & United Kingdom & 2020 \\
\hline
\end{tabular}

\section{Journals' analyses of bibliometrics in the top-30 selected papers}

Because the six selected bibliometrics depicted non-normal distribution, we reported the median, quartiles and IQR. Most of the journals belonged to Q1; $50 \%$ of the top-30 cited articles have an IF above 3.38. The median for the CiteScore was 4.6 and for the Eigenfactor 0.010770. Table 3 shows the descriptive statistics of the bibliometrics from the top-30 cited journals.

The impact factor had a range between one and eleven; the Eigenfactor score for most of the journals remained below 0.0200. The CiteScore seemed to have grouped values within two ranges 0 to five and 10 to 15 . The SNIP had a widespread between 0 and 3 . Values of SJR were primarily concentrated between 0.5 and 3.5. Most of the 
Fig. 2 Bar graph showing the number of publications per month; the dotted line indicates the average number (22) of publications per month

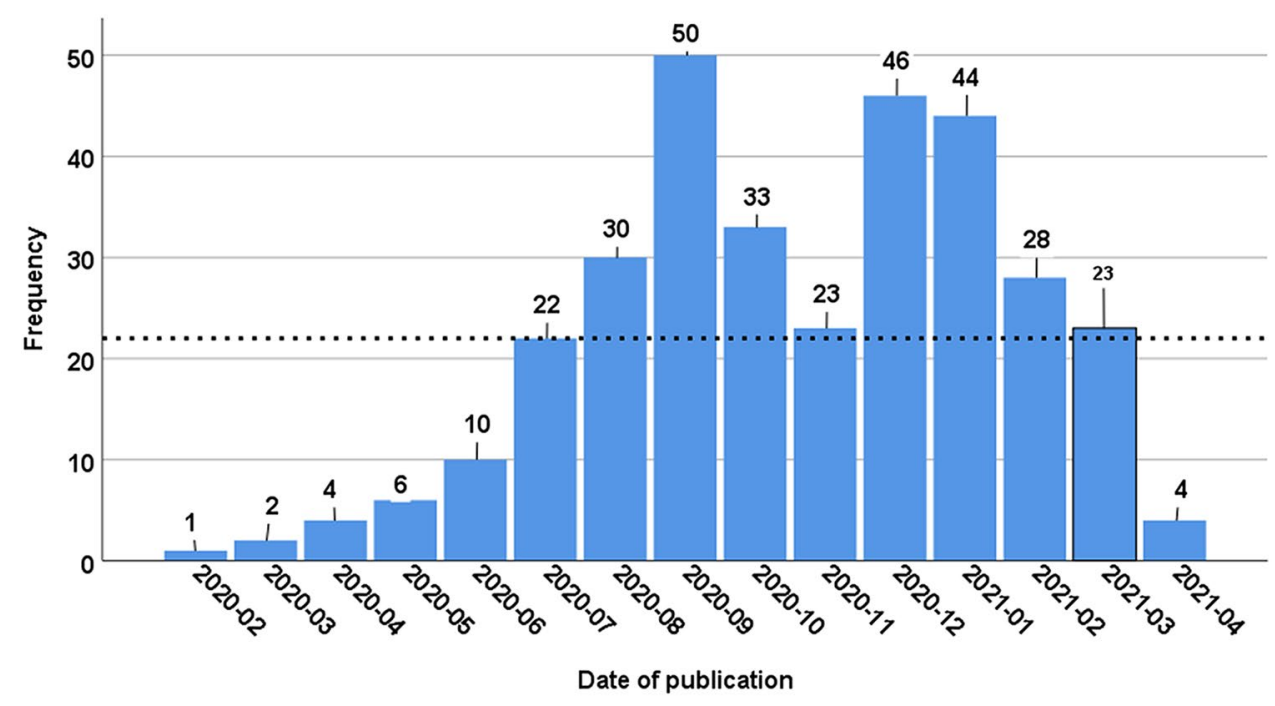

Date of publication

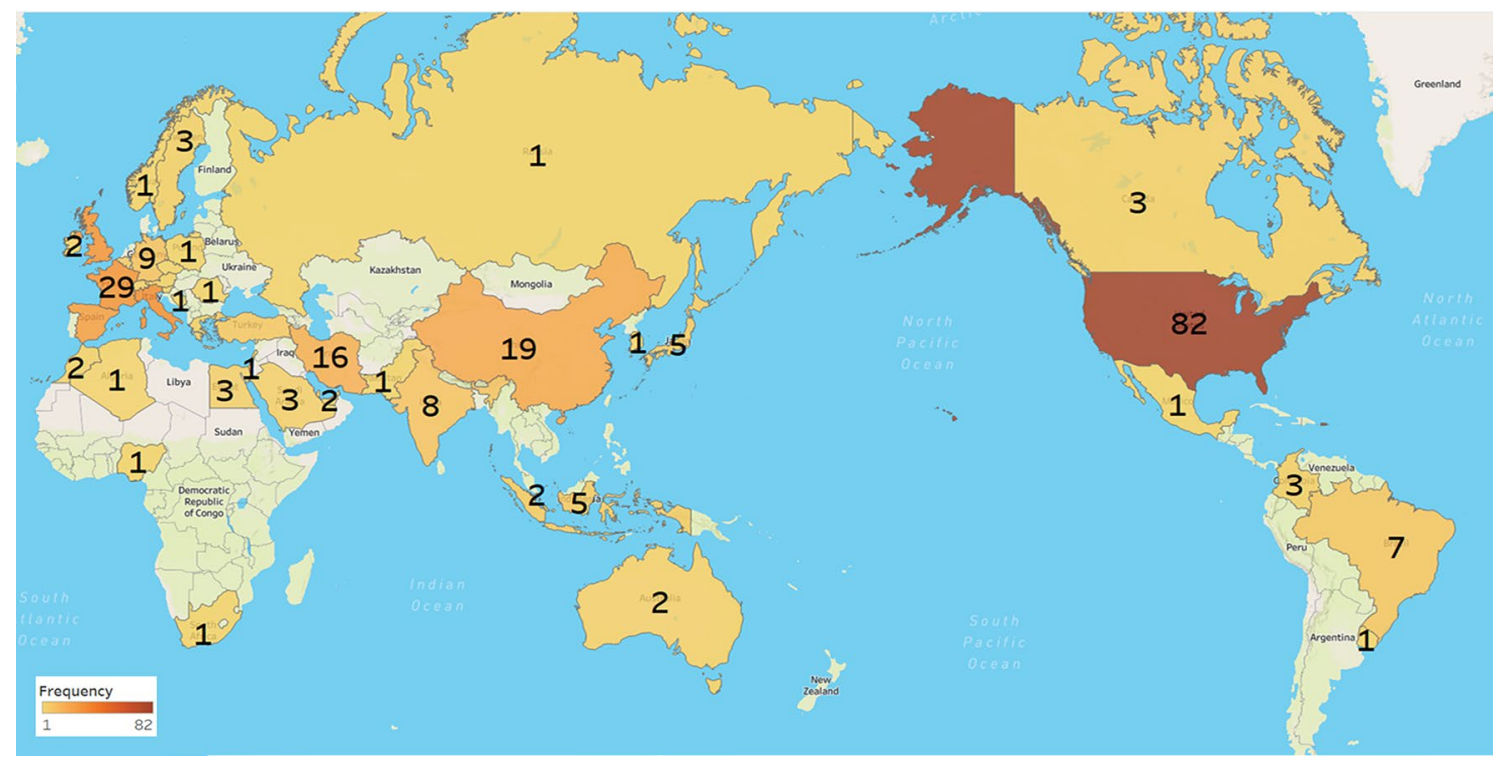

Fig. 3 Global map showing the number of published articles per country

selected journals belong to Q1. Figure A, in the supplemntary file, shows the corresponding bibliometrics' values for the top-30 cited journals using a parallel coordinates plot. A table with the six bibliometrics values corresponding to each top-30 cite selected journal is included as Table F of a supplementary online-only file.

All bibliometrics depicted a positive, mild, to moderate correlation with the total citations. However, except for the impact factor, the correlation between bibliometrics and No. of published articles in each journal depicted a very low or even negative correlation. Figure B, in the supplementrary file, shows scatter plots of the bibliometrics vs total citations correlations and bibliometrics vs No. of published articles.
The strongest, positive correlations (between 70 and 90\%) were observed between the Quartile, SJR and SNIP, with the other metrics. We only found four negative correlations between bibliometrics that were not significant (CiteScore $\Leftrightarrow$ No. of articles, SNIP $\Leftrightarrow$ No. of articles, SJR $\Leftrightarrow$ No. of articles, and Quartile $\Leftrightarrow$ No. of articles). Table G presenting all the Spearman correlation coefficients and p-values is included in the supplementary online-only file.

\section{Global research trends in COVID-19}

We found that $54 \%$ of the studies corresponded to the case report and case series category, $26.8 \%$ were retrospective and only $13.1 \%$ prospective studies. 
Table 2 Top-30 cited journals in COVID-19, MRI and PET/CT research

\begin{tabular}{|c|c|c|c|c|c|}
\hline Rank & Journal & Total Citations & No. of articles & $\begin{array}{l}\text { Average no. of cita- } \\
\text { tions per paper }\end{array}$ & $\begin{array}{l}\% \text { within } \\
\text { Top- } 30 \text { cita- } \\
\text { tions }\end{array}$ \\
\hline 1 & Int J Infect Dis & 674 & 2 & 337 & 24.40 \\
\hline 2 & Radiology & 469 & 9 & 52.11 & 16.98 \\
\hline 3 & Eur J Nucl Med Mol Imaging & 216 & 23 & 9.39 & 7.82 \\
\hline 4 & Brain & 207 & 2 & 103.5 & 7.49 \\
\hline 5 & Neurology & 163 & 6 & 27.17 & 5.90 \\
\hline 6 & Acta Neurochir (Wien) & 110 & 1 & 110 & 3.98 \\
\hline 7 & J Nucl Med & 96 & 4 & 24 & 3.48 \\
\hline 8 & AJNR Am J Neuroradiol & 83 & 5 & 16.6 & 3.01 \\
\hline 9 & Clin Nucl Med & 70 & 22 & 3.18 & 2.53 \\
\hline 10 & Clin Med (Lond) & 68 & 2 & 34 & 2.46 \\
\hline 11 & Neurol Neuroimmunol Neuroinflamm & 62 & 2 & 31 & 2.24 \\
\hline 12 & J Am Coll Radiol & 51 & 3 & 17 & 1.85 \\
\hline 13 & Mult Scler Relat Disord & 45 & 4 & 11.25 & 1.63 \\
\hline 14 & IEEE Rev Biomed Eng & 40 & 1 & 40 & 1.45 \\
\hline 15 & J Gynecol Obstet Hum Reprod & 37 & 1 & 37 & 1.34 \\
\hline 16 & Crit Care & 36 & 1 & 36 & 1.30 \\
\hline 17 & Eur J Neurol & 34 & 3 & 11.33 & 1.23 \\
\hline 18 & BMJ Case Rep & 33 & 9 & 3.67 & 1.19 \\
\hline 19 & EClinicalMedicine & 32 & 2 & 16 & 1.16 \\
\hline 20 & Radiol Case Rep & 31 & 6 & 5.17 & 1.12 \\
\hline 21 & Acad Radiol & 31 & 7 & 4.43 & 1.12 \\
\hline 22 & Nuklearmedizin & 29 & 4 & 7.25 & 1.05 \\
\hline 23 & Stroke & 23 & 1 & 23 & 0.83 \\
\hline 24 & J Neuroimaging & 23 & 2 & 11.5 & 0.83 \\
\hline 25 & Rhinology & 19 & 1 & 19 & 0.69 \\
\hline 26 & Thorax & 18 & 3 & 6 & 0.65 \\
\hline 27 & J Clin Neurosci & 17 & 5 & 3.4 & 0.62 \\
\hline 28 & Cerebellum & 16 & 1 & 16 & 0.58 \\
\hline 29 & Clin Radiol & 15 & 4 & 3.75 & 0.54 \\
\hline \multirow[t]{2}{*}{30} & Clin Neurophysiol Pract & 14 & 1 & 14 & 0.51 \\
\hline & Total & 2762 & & Total & 100.00 \\
\hline
\end{tabular}

Table 3 Descriptive statistics of the bibliometrics from the top-30 cited journals

\begin{tabular}{lllcl}
\hline Bibliometrics & Median & 25 & 75 & IQR \\
\hline IF & 3.381 & 2.220 & 7.457 & 5.237 \\
Eigenfactor & 0.010770 & 0.005825 & 0.030125 & 0.0243 \\
CiteScore & 4.600 & 2.625 & 10.300 & 7.675 \\
SNIP & 1.151 & 0.875 & 1.816 & 0.941 \\
SJR & 1.153 & 0.596 & 2.091 & 1.495 \\
Quartile & 1.000 & 1.000 & 2.000 & 1.000 \\
\hline
\end{tabular}

Regarding the research direction, we identified that up to $74.4 \%$ of the articles belonged to Diagnosis (Clinical Characteristics, Complications), $8.5 \%$ of articles dealt with socio-economic impact, $4 \%$ with treatment, and $3.7 \%$ with pathophysiology.

About the imaging method used, $41.8 \%$ reported only MRI, 29.9\% used only PET/CT, AND 25.6\% of the studies used both imaging techniques. Figure 4 shows bar graphs of the type of study and research directions in COVID-19 using MRI and PET/CT.

\section{Network analysis of the keywords}

We performed a separate network analysis for PubMed, Scopus, and WoS to compare each database's intrinsic variations. Each word was counted once, no matter how many times it appeared in the same article. For the PubMed database, 73 words met the threshold (occurred five times at 
Fig. 4 Type of study (A) and research directions $(\mathbf{B})$ in COVID-19 using MRI and $\mathrm{PET} / \mathrm{CT}$
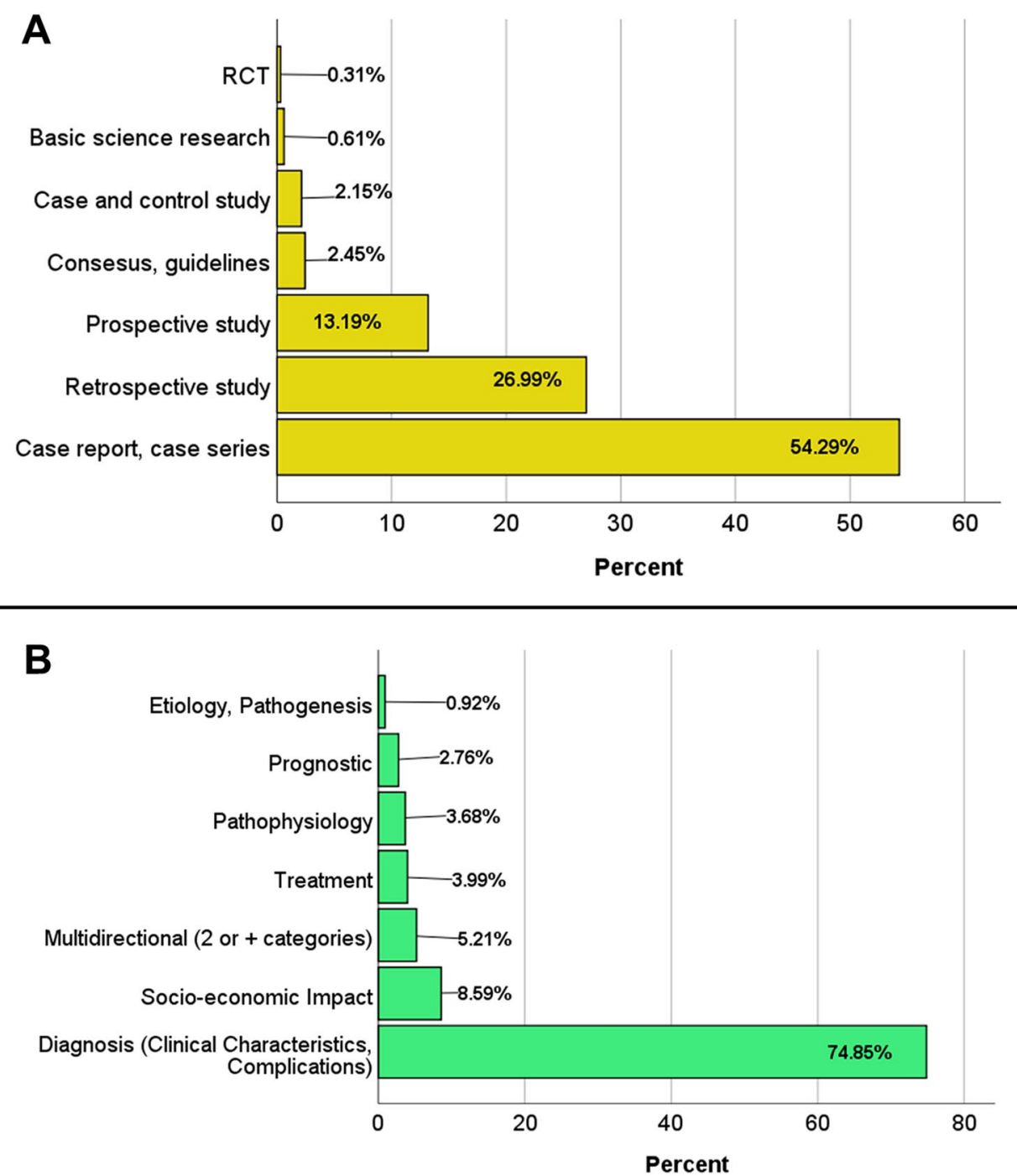

least) in the 866 keywords; in the Scopus database, 316 words met the 2764 keywords; and in the WoS database, 32 words met the threshold in the 660 keywords. Tables $\mathrm{H}$ and I, in the supplmentary file, depict the Total link strength and Co-occurrences of the top-30 keywords in PubMed, Scopus and WoS.

We use the network visualization and density visualization modules of the VOSviewer software. In the density visualization modules, we selected the item density option and rainbow colour pattern. Figures 5(A, C, E) show the score of each node by its colour. Links indicate keyword relevance, and the number of keyword occurrences increases the node size. Nodes are proportional in size and importance.

Graphs from the density visualization module in Figs. 5(B, D, F) show each node's score by its colour. Different colours represent the time when the keyword appears. Red nodes indicate increased weights, and increased size indicates more significant numbers of neighbouring items. Light blue nodes indicate decreased weights and numbers of the neighbouring items. In Fig. 5, the keyword networks are presented related to their original database (A and B, networks from PubMed; C and D, networks from Scopus; E and F networks from WoS).

\section{Discussion}

\section{Goals and selected articles}

In this study, we achieved the aims posed in the introduction; we identified target articles in the three databases analyzed. Then we created a unique database, removed duplicates, and then analysed the selected articles at different dimensions: bibliometrics, demographics, authorship and research trends. From the original 620 articles retrieved, only $52.6 \%$ were selected for the analysis. 
Fig. 5 Keyword networks analysis using the density visualization module of VOSviewer software. A, B, keywords from PubMed; (C, D), keywords from Scopus; (E, F) keywords from WoS
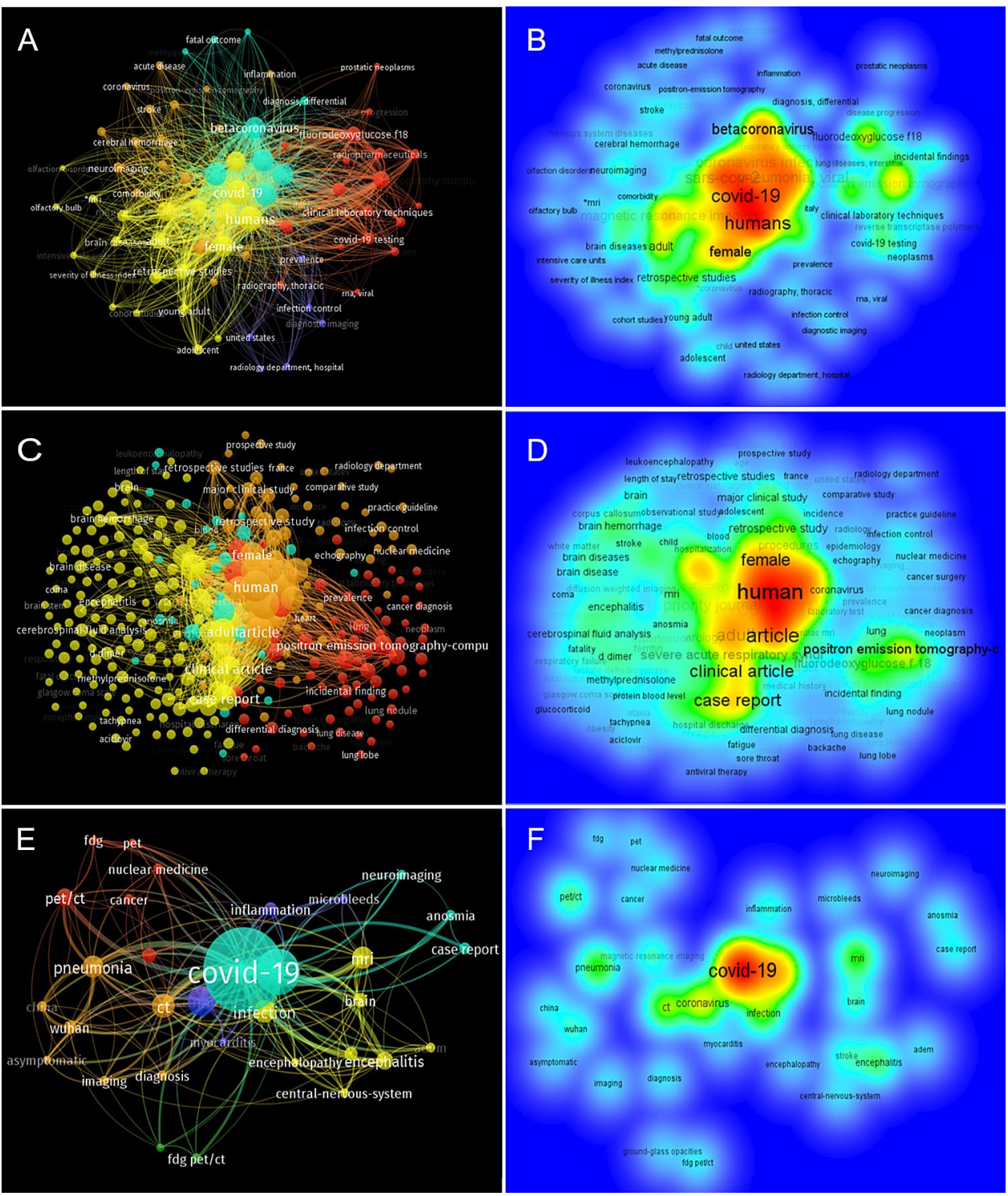

\section{Citation and publication analyses, authorship and mapping of publications}

Citation analysis allowed us to understand the COVID-19 historical perspective and progress of related publications. We can identify seminal papers in the early stage that have impacted the field and act as a surrogate to measure the productivity and influence of a scientist or institution [59]. Our finding of a median of 2 citations per article is similar to the average citation of 2.76 per document reported for studies about COVID during the first 4 months of 2020 in the Scopus database [60].

Although the publication dates spanned only 15 months, that was enough for some articles to be cited more than 100 times. Almost $70 \%$ of the articles were cited in that short period, although $30 \%$ of the articles did not cite at all.
The most cited article was published in a journal (Int J Infect Dis) with an impact factor of 3.202. Authors do not need to publish in a journal with high IF to received citations; also, high IF does not warrant citations. However, it is the content itself of the manuscript that the readers will evaluate as valuable or not.

Neither the IF nor the total number of citations is, per se, the metric of the overall influence of a journal. All journals have diverse citations, and even the best publications contain some papers that are never cited [61]. Citations are not equally distributed, with fewer than $20 \%$ of the articles accounting for more than $50 \%$ of the total number of citations [62, 63].

There were no previous studies of MRI and PET/CT in COVID-19 to compare our findings. A recent study determined that the scientific quality of COVID-19 publications in three of the highest ranked scientific medical journals 
(NEJM, JAMA, The Lancet) is below the quality average of these journals [64].

Future studies will address if the downtrend in the number of publications detected for the first semester of 2021 persists in the middle term. Almost $60 \%$ of the published articles were produced in some countries more affected by COVID-19 (USA, Italy, France, United Kingdom, and Spain).

It is now clear for researchers that the number of people infected is much greater than the number of reported cases. With more publications on our chosen topic, affected people outnumber detected people by one to two orders of magnitude in Spain, the UK, Italy [65]. The three most cited authors had nationalities from Japan, UK and China, which coincides with the most influential countries with the highest Citation Impact related to COVID-19 and Mental Health [66]. The preponderance of articles from developed countries reflects the ample financial resources available to support research by the scientific community.

\section{Journals' bibliometric analyses}

Selected journals had a median IF of 2.488. The average citation per journal was 28.53 ; it was above the number of 23.4 citations per article, reported by a study of 2530 publications about scientific impact in the first months of COVID19 [67]. These numbers are pretty below a previous report of the top-50 cited COVID-19 related articles in which $18 \%$ of articles received more than 2000 citations; also, the general topic of COVID-19 concentrated half of the top-50 cited publications in only three journals (The Lancet, NEJM, and JAMA) [68]. The most cited journal in our study (Int J Infect Dis) received 674 citations; this number is below the 1192 cites received by the Am J Emergency Medicine in a study that reported top emergency medicine journals in terms of COVID-19 publications in 2020 [69].

Strong, positive correlations had been previously reported between total cites and the six selected bibliometrics for the Radiology, nuclear medicine and molecular imaging journals [42]. A correlational study between the number of articles published per journal and their bibliometrics is missing in the literature.

\section{Research trends}

In the last 15 years, various specialities have attempted to identify and analyze the "citation classics" in their field. Some examples of "citation classics" exist in emergency medicine [70], ophthalmology [71], urology [72], obstetrics and gynaecology [73], neurosurgery [74], orthopaedics [75], psychiatrists [76], and digestive diseases [77] among others.

This trend has also evolved to assess the impact of specific medical topics like achalasia [1], diverse techniques like robotic surgery [78], and of course, the early impact of COVID-19 [64, 68]. However, to the best of our knowledge, there was no previous publication of MRI and PET/ $\mathrm{CT}$ research trends in COVID patients.

It was not a surprise that most of the studies were directed to diagnosis, clinical characteristics and complications. Considering MRI and PET/CT and imaging techniques belonging to the speciality of Radiology and medical imaging, there is a dominant role of MRI for reporting these studies; however, $1 / 4$ of the studies is using both imaging techniques, which is a significant achievement for those hospitals than can afford both imaging techniques in the same patient. We are still in an early stage of the pandemic to visualize future directions from a global perspective. However, independent studies started publishing about risk stratification and prognosis based on MRI findings [79].

We agree with previous reviews that, PET/CT cannot substitute or integrate high-resolution $\mathrm{CT}$ to diagnose suspicious COVID-19 or for disease monitoring, also, we learned that up to $48 \%$ of Nuclear Medicine department [80], reported that PET/CT incidentally detected suspicious COVID-19 lesions in patients undergoing standard oncological and non-oncological indications [81]. Also, COVID19 had an impact on Nuclear Medicine departments' daily activities, quantitatively reducing diagnostic and therapeutic procedures up to $51 \%$ [80], and by adapting the security protocols to international guidelines [82]. We believe that medical research will include in the short term the analysis of economic networks into the complexity of COVID-19 emergency [83].

\section{Keyword network analysis}

We observed that each database identified unique keywords that did not appear in other databases and that those keywords were linked to specific articles related to MRI or PET/ CT. In the Total link strength table, the words that caught our attention were PubMed [incidental findings [84], adolescent [85]]; Scopus [case report [86]]; and WoS [encephalitis [87], stroke, [88] microbleeds [89], myocarditis [90]].

Words in the Co-occurrence table unique for each database were in PubMed [retrospective studies [91], clinical laboratory techniques [92]]; Scopus [priority journal [93]]; and WoS [cancer [94], asymptomatic [95], microbleeds [89], myocarditis [90]]. These words can be considered research hotspots.

\section{Limitations of the study}

We only included articles published in English from the WoS, Scopus and PubMed databases; with this approach, we may have lost sight of influential articles published in other languages and included in other databases. This strategy may 
imply some degree of selection bias if we could not identify all available data on the topic; however, we intentionally excluded reviews and grey literature. Readers should be aware that the critical appraisal of the risk of bias in scoping reviews is not considered mandatory [96]. Systematic reviews commonly select the information sources by requiring specific study types, such as RCT, and imposing quality standards, such as adequate allocation concealment, and emphasise synthesizing data to address a specific research question [96]. On the contrary, a scoping review describes existing literature and commonly includes findings from various study designs and methods; in our case, we included case reports, case series and guidelines [31]. The synthesis of findings from individual studies and the generation of 'summary' findings is not mandatory in a scoping review [97]. Since the scope of our study was relatively wide, it was not able to perform a systematic quantitative review as Guzman-Ortiz et al. conducted [36].

To avoid the bias of time on citation number, we include all articles that meet our inclusion criteria, even those with zero citations; we wanted to prevent the exclusion of articles published in the last months that, because they still did not receive citations, they were not going to be in the list of selected papers. We acknowledge that our per-month analysis of publication and total citations for papers published in the last 15 months is a snapshot of publications that, over time, many of them may accrue enough citations and move into the top 100 articles. Citation of scientific papers usually begins $1-2$ years after publication generally reaches a maximum after 3-10 years and then tapers off to a lower rate [59]. It may take two decades to more accurately assess the true impact of a publication [98].

\section{Conclusions}

COVID-19 pandemic is still spreading worldwide, and the knowledge about its different facets continues advancing. MRI or PET/CT is used in more than 50\% of the selected studies. We identified research trends spanning seven categories, no only the diagnostic but others are emerging like socio-economic impact and pathogenesis. There are already some articles with more than 100 citations that can be considered seminals in this field. Developed countries had an advantage by having a hospital with more resources and MRI and PET/CT resources in the same institution to supplement basic assessment in patients with COVID-19.

Supplementary Information The online version contains supplementary material available at https://doi.org/10.1007/s40336-021-00460-x.

Acknowledgements NRS was a research fellow at Directorate of Research, Hospital General de Mexico "Dr Eduardo Liceaga", under supervision of ERV during 2021.
Author contributions Conceptualisation: NRS and ERV; methodology: NRS, RGVA, and ERV; software: NRS, RGVA, and ERV; validation: NRS, RGVA, SKT, and ERV; formal analysis: ERV; investigation: NRS, RGVA, and ERV; resources: ERV; data curation: NRS and RGVA; writing-original draft preparation: NRS, RGVA, SKT, and ERV; writing - review and editing: NRS, RGVA, SKT, and ERV; visualisation: NRS, and ERV; supervision: ERV; project administration: ERV; funding acquisition: N/A. All authors have read and agreed to the published version of the manuscript.

Funding This research received no specific grant from any funding agency in the public, commercial, or not-for-profit sectors.

Data availability The data used to support this study's findings are available from the corresponding author upon reasonable request.

\section{Declarations}

Conflict of interest The authors declare that there is no conflict of interest regarding the publication of this article.

\section{References}

1. Xia H, Tan S, Huang S, Gan P, Zhong C, Lu M et al (2021) Scoping review and bibliometric analysis of the most influential publications in achalasia research from 1995 to 2020 . Biomed Res Int 2021:8836395. https://doi.org/10.1155/2021/8836395

2. Song F, Shi N, Shan F, Zhang Z, Shen J, Lu H et al (2020) Emerging 2019 novel coronavirus (2019-nCoV) pneumonia. Radiology 295:210-217. https://doi.org/10.1148/radiol.2020200274

3. Kooraki S, Hosseiny M, Myers L, Gholamrezanezhad A (2020) Coronavirus (COVID-19) outbreak: what the department of radiology should know. J Am Coll Radiol 17:447-451. https://doi.org/ 10.1016/j.jacr.2020.02.008

4. Carotti M, Salaffi F, Sarzi-Puttini P, Agostini A, Borgheresi A, Minorati D et al (2020) Chest CT features of coronavirus disease 2019 (COVID-19) pneumonia: key points for radiologists. Radiol Med 125:636-646. https://doi.org/10.1007/s11547-020-01237-4

5. Zhu N, Zhang D, Wang W, Li X, Yang B, Song J et al (2020) A novel Coronavirus from patients with pneumonia in China, 2019. N Engl J Med 382:727-733. https://doi.org/10.1056/NEJMoa2001 017

6. Albano D, Bertagna F, Alongi P, Baldari S, Baldoncini A, Bartolomei $\mathrm{M}$ et al (2021) Prevalence of interstitial pneumonia suggestive of COVID-19 at (18)F-FDG PET/CT in oncological asymptomatic patients in a high prevalence country during pandemic period: a national multi-centric retrospective study. Eur J Nucl Med Mol Imaging 48:2871-2882. https://doi.org/10.1007/ s00259-021-05219-0

7. Fields BKK, Demirjian NL, Dadgar H, Gholamrezanezhad A (2020) Imaging of COVID-19: CT, MRI, and PET. Semin Nucl Med. https://doi.org/10.1053/j.semnuclmed.2020.11.003

8. Zhao W, Zhong Z, Xie X, Yu Q, Liu J (2020) Relation between chest CT findings and clinical conditions of Coronavirus Disease (COVID-19) Pneumonia: a multicenter study. AJR Am J Roentgenol 214:1072-1077. https://doi.org/10.2214/AJR.20.22976

9. Xie X, Zhong Z, Zhao W, Zheng C, Wang F, Liu J (2020) Chest CT for typical Coronavirus Disease 2019 (COVID-19) pneumonia: relationship to negative RT-PCR testing. Radiology 296:E41E45. https://doi.org/10.1148/radiol.2020200343

10. Lan L, Xu D, Ye G, Xia C, Wang S, Li Y et al (2020) Positive RTPCR test results in patients recovered From COVID-19. JAMA 
J Am Med Assoc 323:1502-1503. https://doi.org/10.1001/jama. 2020.2783

11. Dong D, Tang Z, Wang S, Hui H, Gong L, Lu Y et al (2021) The role of imaging in the detection and management of COVID-19: a review. IEEE Rev Biomed Eng 14:16-29. https://doi.org/10.1109/ RBME.2020.2990959

12. Revel MP, Parkar AP, Prosch H, Silva M, Sverzellati N, Gleeson $F$ et al (2020) COVID-19 patients and the radiology department - advice from the European Society of Radiology (ESR) and the European Society of Thoracic Imaging (ESTI). Eur Radiol 30:4903-4909. https://doi.org/10.1007/s00330-020-06865-y

13. Ojha V, Mani A, Pandey NN, Sharma S, Kumar S (2020) CT in coronavirus disease 2019 (COVID-19): a systematic review of chest CT findings in 4410 adult patients. Eur Radiol 30:61296138. https://doi.org/10.1007/s00330-020-06975-7

14. Torkian P, Rajebi H, Zamani T, Ramezani N, Kiani P, Akhlaghpoor S (2021) Magnetic resonance imaging features of coronavirus disease 2019 (COVID-19) pneumonia: the first preliminary case series. Clin Imaging 69:261-265. https://doi.org/10.1016/j. clinimag.2020.09.002

15. Ates OF, Taydas O, Dheir H (2020) Thorax magnetic resonance imaging findings in patients with Coronavirus Disease (COVID19). Acad Radiol 27:1373-1378. https://doi.org/10.1016/j.acra. 2020.08.009

16. Yang S, Zhang Y, Shen J, Dai Y, Ling Y, Lu H et al (2020) Clinical potential of UTE-MRI for assessing COVID-19: patient- and lesion-based comparative analysis. J Magn Reson Imaging 52:397-406. https://doi.org/10.1002/jmri.27208

17. Kooraki S, Hosseiny M, Raman SS, Myers L, Gholamrezanezhad A (2020) Coronavirus disease 2019 (COVID-19) Precautions: what the MRI suite should know. J Am Coll Radiol 17:830. https://doi.org/10.1016/j.jacr.2020.05.018

18. Syrjala H, Broas M, Ohtonen P, Jartti A, Paakko E (2017) Chest magnetic resonance imaging for pneumonia diagnosis in outpatients with lower respiratory tract infection. Eur Respir J. https:// doi.org/10.1183/13993003.01303-2016

19. Caro-Dominguez P, Shelmerdine SC, Toso S, Secinaro A, Toma P, Damasio MB et al (2020) Thoracic imaging of coronavirus disease 2019 (COVID-19) in children: a series of 91 cases. Pediatr Radiol 50:1354-1368. https://doi.org/10.1007/s00247-020-04747-5

20. Katal S, Amini H, Gholamrezanezhad A (2021) PET in the diagnostic management of infectious/inflammatory pulmonary pathologies: a revisit in the era of COVID-19. Nucl Med Commun 42:3-8. https://doi.org/10.1097/MNM.0000000000001299

21. Deng Y, Lei L, Chen Y, Zhang W (2020) The potential added value of FDG PET/CT for COVID-19 pneumonia. Eur J Nucl Med Mol Imaging 47:1634-1635. https://doi.org/10.1007/ s00259-020-04767-1

22. Capitanio S, Nordin AJ, Noraini AR, Rossetti C (2016) PET/CT in nononcological lung diseases: current applications and future perspectives. Eur Respir Rev 25:247-258. https://doi.org/10.1183/ 16000617.0051-2016

23. Chefer S, Thomasson D, Seidel J, Reba RC, Bohannon JK, Lackemeyer MG et al (2015) Modeling [(18)F]-FDG lymphoid tissue kinetics to characterize nonhuman primate immune response to Middle East respiratory syndrome-coronavirus aerosol challenge. EJNMMI Res 5:65. https://doi.org/10.1186/ s13550-015-0143-x

24. Haagmans BL, van den Brand JM, Provacia LB, Raj VS, Stittelaar KJ, Getu $S$ et al (2015) Asymptomatic middle east respiratory syndrome coronavirus infection in rabbits. J Virol 89:6131-6135. https://doi.org/10.1128/JVI.00661-15

25. Qin C, Liu F, Yen TC, Lan X (2020) (18)F-FDG PET/CT findings of COVID-19: a series of four highly suspected cases. Eur J Nucl Med Mol Imaging 47:1281-1286. https://doi.org/10.1007/ s00259-020-04734-w
26. Zou S, Zhu X (2020) FDG PET/CT of COVID-19. Radiology 296:E118. https://doi.org/10.1148/radiol.2020200770

27. Rafiee F, Keshavarz P, Katal S, Assadi M, Nejati SF, Ebrahimian Sadabad F et al (2021) Coronavirus Disease 2019 (COVID19) in molecular imaging: a systematic review of incidental detection of SARS-CoV-2 pneumonia on PET studies. Semin Nucl Med 51:178-191. https://doi.org/10.1053/j.semnuclmed. 2020.10.002

28. Scarlattei M, Baldari G, Silva M, Bola S, Sammartano A, Migliari $S$ et al (2020) Unknown SARS-CoV-2 pneumonia detected by PET/CT in patients with cancer. Tumori 106:325-332. https:// doi.org/10.1177/0300891620935983

29. Lutje S, Marinova M, Kutting D, Attenberger U, Essler M, Bundschuh RA (2020) Nuclear medicine in SARS-CoV-2 pandemia: 18F-FDG-PET/CT to visualize COVID-19. Nuklearmedizin 59:276-280. https://doi.org/10.1055/a-1152-2341

30. Kamani CH, Jreige M, Pappon M, Fischbacher A, Borens O, Monney $\mathrm{P}$ et al (2020) Added value of (18)F-FDG PET/CT in a SARS-CoV-2-infected complex case with persistent fever. Eur J Nucl Med Mol Imaging 47:2036-2037. https://doi.org/10.1007/ s00259-020-04860-5

31. Davis K, Drey N, Gould D (2009) What are scoping studies? A review of the nursing literature. Int J Nurs Stud 46:1386-1400. https://doi.org/10.1016/j.ijnurstu.2009.02.010

32. Arksey H, O'Malley L (2005) Scoping studies: towards a methodological framework. Int J Soc Res Methodol 8:19-32. https:// doi.org/10.1080/1364557032000119616

33. Levac D, Colquhoun H, O'Brien KK (2010) Scoping studies: advancing the methodology. Implement Sci 5:69. https://doi.org/ 10.1186/1748-5908-5-69

34. Peters MD, Godfrey CM, Khalil H, McInerney P, Parker D, Soares CB (2015) Guidance for conducting systematic scoping reviews. Int J Evid Based Healthc 13:141-146. https://doi.org/10.1097/ XEB.0000000000000050

35. Tricco AC, Lillie E, Zarin W, O'Brien KK, Colquhoun H, Levac $D$ et al (2018) PRISMA extension for scoping reviews (PRISMAScR): checklist and explanation. Ann Intern Med 169:467-473. https://doi.org/10.7326/M18-0850

36. Guzman-Ortiz E, Bueno-Hernandez N, Melendez-Mier G, RoldanValadez E (2021) Quantitative systematic review: methods used for the in vivo measurement of body composition in pregnancy. $\mathrm{J}$ Adv Nurs 77:537-549. https://doi.org/10.1111/jan.14594

37. Kanne JP, Little BP, Chung JH, Elicker BM, Ketai LH (2020) Essentials for radiologists on COVID-19: an update-radiology scientific expert panel. Radiology 296:E113-E114. https://doi. org/10.1148/radiol.2020200527

38. Shi H, Han X, Jiang N, Cao Y, Alwalid O, Gu J et al (2020) Radiological findings from 81 patients with COVID-19 pneumonia in Wuhan, China: a descriptive study. Lancet Infect Dis 20:425-434. https://doi.org/10.1016/S1473-3099(20)30086-4

39. Lee EYP, Ng MY, Khong PL (2020) COVID-19 pneumonia: what has CT taught us? Lancet Infect Dis 20:384-385. https://doi.org/ 10.1016/S1473-3099(20)30134-1

40. Roldan-Valadez E, Salazar-Ruiz SY, Ibarra-Contreras R, Rios C (2019) Current concepts on bibliometrics: a brief review about impact factor, Eigenfactor score, CiteScore, SCImago Journal Rank, Source-Normalised Impact per Paper, H-index, and alternative metrics. Ir J Med Sci 188:939-951. https://doi.org/10.1007/ s11845-018-1936-5

41. van Eck NJ, Waltman L (2010) Software survey: VOSviewer, a computer program for bibliometric mapping. Scientometrics 84:523-538. https://doi.org/10.1007/s11192-009-0146-3

42. Villasenor-Almaraz M, Islas-Serrano J, Murata C, Roldan-Valadez E (2019) Impact factor correlations with Scimago journal rank, source normalized impact per paper, eigenfactor score, and the citescore in radiology, nuclear medicine \& medical imaging 
journals. Radiol Med 124:495-504. https://doi.org/10.1007/ s11547-019-00996-z

43. Hernandez-Galvez DC, Roldan-Valadez E (2019) Mexican ENARM: performance comparison of public vs. private medical schools, geographic and socioeconomic regions. Salud Publica Mex 61:637-647. https://doi.org/10.21149/10078

44. Mendoza-Aguilar AN, Salazar-Ruiz SY, Cardiel-Marmolejo LE, Roldan-Valadez E (2020) Comparison of scores achieved by foreign medical graduates in the National Evaluation for Medical Residency (ENARM) in Mexico. Postgrad Med J 96:108-109. https://doi.org/10.1136/postgradmedj-2019-136893

45. Cedillo-Pozos A, Mendoza-Aguilar AN, Roldan-Valadez E (2021) Comparison between Mexican and International Medical Graduates' scores obtained in the ENARM competing for surgical specialties in Mexico during 2012-2019: data visualization, trend and forecasting analyses. Cir Cir 89:22-32. https://doi.org/10.24875/ CIRU.19001670

46. Albano D, Bertagna F, Bertoli M, Bosio G, Lucchini S, Motta $F$ et al (2020) Incidental findings suggestive of COVID-19 in asymptomatic patients undergoing nuclear medicine procedures in a high-prevalence region. J Nucl Med 61:632-636. https://doi. org/10.2967/jnumed.120.246256

47. Bhayana R, Som A, Li MD, Carey DE, Anderson MA, Blake MA et al (2020) Abdominal imaging findings in COVID-19: preliminary observations. Radiology 297:E207-E215. https://doi.org/10. 1148/radiol.2020201908

48. Coolen T, Lolli V, Sadeghi N, Rovai A, Trotta N, Taccone FS et al (2020) Early postmortem brain MRI findings in COVID-19 nonsurvivors. Neurology 95:e2016-e2027. https://doi.org/10.1212/ WNL.0000000000010116

49. Dixon L, Varley J, Gontsarova A, Mallon D, Tona F, Muir D et al (2020) COVID-19-related acute necrotizing encephalopathy with brain stem involvement in a patient with aplastic anemia. Neurol Neuroimmunol Neuroinflamm. https://doi.org/10.1212/NXI. 0000000000000789

50. Hernandez-Fernandez F, Sandoval Valencia H, Barbella-Aponte RA, Collado-Jimenez R, Ayo-Martin O, Barrena C et al (2020) Cerebrovascular disease in patients with COVID-19: neuroimaging, histological and clinical description. Brain 143:3089-3103. https://doi.org/10.1093/brain/awaa239

51. Kandemirli SG, Dogan L, Sarikaya ZT, Kara S, Akinci C, Kaya $D$ et al (2020) Brain MRI findings in patients in the intensive care unit with COVID-19 infection. Radiology 297:E232-E235. https://doi.org/10.1148/radiol.2020201697

52. Kremer S, Lersy F, de Seze J, Ferre JC, Maamar A, Carsin-Nicol $B$ et al (2020) Brain MRI findings in severe COVID-19: a retrospective observational study. Radiology 297:E242-E251. https:// doi.org/10.1148/radiol.2020202222

53. Moriguchi T, Harii N, Goto J, Harada D, Sugawara H, Takamino J et al (2020) A first case of meningitis/encephalitis associated with SARS-Coronavirus-2. Int J Infect Dis 94:55-58. https://doi.org/ 10.1016/j.ijid.2020.03.062

54. Paterson RW, Brown RL, Benjamin L, Nortley R, Wiethoff S, Bharucha $\mathrm{T}$ et al (2020) The emerging spectrum of COVID-19 neurology: clinical, radiological and laboratory findings. Brain 143:3104-3120. https://doi.org/10.1093/brain/awaa240

55. Radmanesh A, Derman A, Lui YW, Raz E, Loh JP, Hagiwara M et al (2020) COVID-19-associated diffuse leukoencephalopathy and microhemorrhages. Radiology 297:E223-E227. https://doi. org/10.1148/radiol.2020202040

56. Virhammar J, Kumlien E, Fallmar D, Frithiof R, Jackmann S, Skold MK et al (2020) Acute necrotizing encephalopathy with SARS-CoV-2 RNA confirmed in cerebrospinal fluid. Neurology 95:445-449. https://doi.org/10.1212/WNL.0000000000010250

57. Wong PF, Craik S, Newman P, Makan A, Srinivasan K, Crawford E et al (2020) Lessons of the month 1: a case of rhombencephalitis as a rare complication of acute COVID-19 infection. Clin Med (Lond). https://doi.org/10.7861/clinmed. 2020-0182

58. Zanin L, Saraceno G, Panciani PP, Renisi G, Signorini L, Migliorati K et al (2020) SARS-CoV-2 can induce brain and spine demyelinating lesions. Acta Neurochir (Wien) 162:1491-1494. https:// doi.org/10.1007/s00701-020-04374-x

59. Loomes DE, van Zanten SV (2013) Bibliometrics of the top 100 clinical articles in digestive disease. Gastroenterology 144:673-6 e5. https://doi.org/10.1053/j.gastro.2013.02.013

60. Dehghanbanadaki H, Seif F, Vahidi Y, Razi F, Hashemi E, Khoshmirsafa $\mathrm{M}$ et al (2020) Bibliometric analysis of global scientific research on Coronavirus (COVID-19). Med J Islam Repub Iran 34:51. https://doi.org/10.34171/mjiri.34.51

61. Fersht A (2009) The most influential journals: impact Factor and Eigenfactor. Proc Natl Acad Sci USA 106:6883-6884. https://doi. org/10.1073/pnas.0903307106

62. Callaham M, Wears RL, Weber E (2002) Journal prestige, publication bias, and other characteristics associated with citation of published studies in peer-reviewed journals. JAMA J Am Med Assoc 287:2847-2850

63. Weale AR, Bailey M, Lear PA (2004) The level of non-citation of articles within a journal as a measure of quality: a comparison to the impact factor. BMC Med Res Methodol 4:14. https://doi.org/ 10.1186/1471-2288-4-14

64. Zdravkovic M, Berger-Estilita J, Zdravkovic B, Berger D (2021) Correction: Scientific quality of COVID-19 and SARS CoV-2 publications in the highest impact medical journals during the early phase of the pandemic: a case control study. PLoS ONE 16:e0250141. https://doi.org/10.1371/journal.pone.0250141

65. Tiwari S, Vyasarayani CP, Chatterjee A (2021) Data suggest COVID-19 affected numbers greatly exceeded detected numbers, in four European countries, as per a delayed SEIQR model. Sci Rep 11:8106. https://doi.org/10.1038/s41598-021-87630-z

66. Gul S, Rehman SU, Ashiq M, Khattak A (2020) Mapping the scientific literature on COVID-19 and mental health. Psychiatr Danub 32:463-471. https://doi.org/10.24869/psyd.2020.463

67. Dieguez-Campa CE, Perez-Neri I, Reyes-Teran G, Flores-Apodaca IA, Castillo-Ledon-Pretelini J, Mercado-Bautista O et al (2020) The research pandemic: a bibliometric analysis of publications on COVID-19 and their scientific impact during the first months. Arch Cardiol Mex. https://doi.org/10.24875/ACM.20000370

68. ElHawary H, Salimi A, Diab N, Smith L (2020) Bibliometric analysis of early COVID-19 research: the top 50 cited papers. Infect Dis (Auckl) 13:1178633720962935. https://doi.org/10. 1177/1178633720962935

69. Erenler AK, Baydin A (2021) Comparison of performances of top emergency medicine journals in terms of COVID-19 publications in 2020. Am J Emerg Med 46:132-136. https://doi.org/10.1016/j. ajem.2021.03.003

70. Tsai YL, Lee CC, Chen SC, Yen ZS (2006) Top-cited articles in emergency medicine. Am J Emerg Med 24:647-654. https://doi. org/10.1016/j.ajem.2006.01.001

71. Ohba N, Nakao K, Isashiki Y, Ohba A (2007) The 100 most frequently cited articles in ophthalmology journals. Arch Ophthalmol 125:952-960. https://doi.org/10.1001/archopht.125.7.952

72. Hennessey K, Afshar K, Macneily AE (2009) The top 100 cited articles in urology. Can Urol Assoc J 3:293-302. https://doi.org/ 10.5489/cuaj.1123

73. Brandt JS, Downing AC, Howard DL, Kofinas JD, Chasen ST (2010) Citation classics in obstetrics and gynecology: the 100 most frequently cited journal articles in the last 50 years. Am J Obstet Gynecol 203(355):e1-7. https://doi.org/10.1016/j.ajog. 2010.07.025

74. Ponce FA, Lozano AM (2010) Highly cited works in neurosurgery. Part I: the 100 top-cited papers in neurosurgical journals. J 
Neurosurg 112:223-232. https://doi.org/10.3171/2009.12.JNS09 1599

75. Lefaivre KA, Shadgan B, O'Brien PJ (2011) 100 most cited articles in orthopaedic surgery. Clin Orthop Relat Res 469:14871497. https://doi.org/10.1007/s11999-010-1604-1

76. Mazhari S (2013) The 100 top-cited articles published in psychiatric journals. J Psychiatr Pract 19:327-338. https://doi.org/10. 1097/01.pra.0000432604.06835.da

77. Tang X, Gong W, Yuan F, Li R, Han X, Huang S et al (2016) Top-cited articles in digestive system disease from 1950 to 2013. J Gastroenterol Hepatol 31:107-111. https://doi.org/10.1111/jgh. 13032

78. Connelly TM, Malik Z, Sehgal R, Byrnes G, Coffey JC, Peirce C (2020) The 100 most influential manuscripts in robotic surgery: a bibliometric analysis. J Robot Surg 14:155-165. https://doi.org/ 10.1007/s11701-019-00956-9

79. Sanghvi SK, Schwarzman LS, Nazir NT (2021) Cardiac MRI and myocardial injury in COVID-19: diagnosis, risk stratification and prognosis. Diagnostics (Basel). https://doi.org/10.3390/diagnostic s11010130

80. Annunziata S, Bauckneht M, Albano D, Argiroffi G, Calabro $\mathrm{D}$, Abenavoli $\mathrm{E}$ et al (2020) Impact of the COVID-19 pandemic in nuclear medicine departments: preliminary report of the first international survey. Eur J Nucl Med Mol Imaging 47:2090-2099. https://doi.org/10.1007/s00259-020-04874-z

81. Annunziata S, Delgado Bolton RC, Kamani CH, Prior JO, Albano $\mathrm{D}$, Bertagna $\mathrm{F}$ et al (2020) Role of 2-[(18)F]FDG as a radiopharmaceutical for PET/CT in patients with COVID-19: a systematic review. Pharmaceuticals (Basel). https://doi.org/10.3390/ph131 10377

82. Annunziata S, Albano D, Laudicella R, Bauckneht M, Young Committee of the Italian Association of Nuclear M (2020) Surveys on COVID-19 in nuclear medicine: what happened and what we learned. Clin Transl Imaging. https://doi.org/10.1007/ s40336-020-00391-z

83. Lo Re M, Parente F, Annunziata S (2021) Economic networks in the complexity of COVID-19 emergency. A qualitative approach for an actor-network model. L'industria. https://doi.org/10.1430/ 100322

84. Marti A, Moron S, Gonzalez E, Rojas J (2020) Incidental findings of COVID-19 in F18-FDG PET/CT from asymptomatic patients with cancer in two healthcare institutions in Bogota Colombia. Biomedica 40:27-33. https://doi.org/10.7705/biomedica.5833

85. Drum E, McClung Pasqualino H, Subramanyam R (2020) Anesthesia and potential aerosol generation during magnetic resonance imaging in children with COVID-19. Paediatr Anaesth 30:944946. https://doi.org/10.1111/pan.13951

86. AlKetbi R, AlNuaimi D, AlMulla M, AlTalai N, Samir M, Kumar $\mathrm{N}$ et al (2020) Acute myelitis as a neurological complication of Covid-19: a case report and MRI findings. Radiol Case Rep 15:1591-1595. https://doi.org/10.1016/j.radcr.2020.06.001

87. Sattar SBA, Haider MA, Zia Z, Niazi M, Iqbal QZ (2020) Clinical, radiological, and molecular findings of acute encephalitis in a
COVID-19 patient: a rare case report. Cureus 12:e10650. https:// doi.org/10.7759/cureus.10650

88. Farooque U, Shabih S, Karimi S, Lohano AK, Kataria S (2020) Coronavirus disease 2019-related acute ischemic stroke: a case report. Cureus 12:e10310. https://doi.org/10.7759/cureus.10310

89. Fitsiori A, Pugin D, Thieffry C, Lalive P, Vargas MI (2020) COVID-19 is associated with an unusual pattern of brain microbleeds in critically Ill patients. J Neuroimaging 30:593-597. https://doi.org/10.1111/jon.12755

90. Cuomo G, Menozzi M, Carli F, Digaetano M, Raimondi A, Reggianini L et al (2020) Acute myocarditis as the main clinical manifestation of SARS-CoV 2 infection. Infect Dis Rep 12:8609. https://doi.org/10.4081/idr.2020.8609

91. Freeman CW, Masur J, Hassankhani A, Wolf RL, Levine JM, Mohan S (2021) Coronavirus disease (COVID-19)-related disseminated leukoencephalopathy: a retrospective study of findings on brain MRI. AJR Am J Roentgenol 216:1046-1047. https://doi. org/10.2214/AJR.20.24364

92. Jiang ZZ, He C, Wang DQ, Shen HL, Sun JL, Gan WN et al (2020) The Role of imaging techniques in management of COVID-19 in China: from diagnosis to monitoring and follow-up. Med Sci Monit 26:e924582. https://doi.org/10.12659/MSM.924582

93. Ali SA, Abdelkawi MM (2020) Incidentally recognized COVID19 pneumonia in routine oncologic 18F-FDG PET/CT examinations: a local experience during pandemic era. Egypt J Radiol Nucl Med. https://doi.org/10.1186/s43055-020-00333-9

94. Setti L, Bonacina M, Meroni R, Kirienko M, Galli F, Dalto SC et al (2020) Increased incidence of interstitial pneumonia detected on [(18)F]-FDG-PET/CT in asymptomatic cancer patients during COVID-19 pandemic in Lombardy: a casualty or COVID-19 infection? Eur J Nucl Med Mol Imaging. https://doi.org/10.1007/ s00259-020-05027-y

95. Koffi NP, Abad CEA, Miloud G, Brahim EM (2020) Not all anosmia and fever was COVID-19 infection: a case report. Pan Afr Med J 37:5. https://doi.org/10.11604/pamj.2020.37.371.27014

96. Sucharew H, Macaluso M (2019) Progress notes: methods for research evidence synthesis: the scoping review approach. J Hosp Med 14:416-418. https://doi.org/10.12788/jhm.3248

97. Munn Z, Peters MDJ, Stern C, Tufanaru C, McArthur A, Aromataris E (2018) Systematic review or scoping review? Guidance for authors when choosing between a systematic or scoping review approach. BMC Med Res Methodol 18:143. https://doi.org/10. 1186/s12874-018-0611-x

98. Dubin D, Hafner AW, Arndt KA (1993) Citation classics in clinical dermatologic journals. Citation analysis, biomedical journals, and landmark articles, 1945-1990. Arch Dermatol 129:1121-1129

Publisher's Note Springer Nature remains neutral with regard to jurisdictional claims in published maps and institutional affiliations. 